\title{
Relationship of Maxillary Incisor Angulation with Upper Lip Strain
}

\section{Pricillia Priska Sianita*}

Department of Orthodontics Faculty of Dentistry Professor. DR. Moestopo

University, South Jakarta, Indonesia

*Corresponding Author: Pricillia Priska Sianita, Department of Orthodontics

Faculty of Dentistry Professor. DR. Moestopo University, South Jakarta, Indonesia.
Received: December 17, 2021

Published: January 06, 2022

(C) All rights are reserved by Pricillia Priska

Sianita.

\section{Abstract}

Background: In orthodontic treatment, cephalometric analysis is always carried out to obtain information that can help diagnose cases and develop the best treatment plan that can produce a good dental arrangement, a charming smile and an attractive profile. One of the measurements taken is to determine the angulation of the maxillary incisors because in almost every orthodontic case, the maxillary incisors, which are located in the anterior region, are the main areas where tooth movement occurs. In addition, this change in maxillary incisor angulation is expected to affect the position of the upper lip which in turn will affect the patient's profile. However, the position of the upper lip is also affected by the thickness and tension of the soft tissues of the upper lip.

Objective: This study was conducted to determine the relationship between maxillary incisor angulation and upper lip strain.

Materials and methods: A total of 52 lateral cephalograms from deutero-Malay sub-race subjects with Angle class II division 1 malocclusion which has an overjet characteristic of greater than $6 \mathrm{~mm}$ resulting in a convex profile are the subjects in this study. The maxillary incisor angulation was measured through the angle formed by the intersection of the long axis of the maxillary incisor with the sella-nasion line (S-N), while the upper lip tension was determined by assessing the strain factor. The measurement data were analyzed statistically using a correlation test to see how the relationship between the two variables in this study was

Results: Maxillary incisor angulation was shown to have a significant relationship $(\mathrm{p}<0.05)$ with upper lip strain and this relationship got stronger as the measurement results increased in the related variables.

Conclusion: Proclination or retroclination of maxillary incisors showed a significant relationship with upper lip strain. Increasing the value of each variable will further strengthen the relationship.

Keywords: Angulation of Maxillary Incisors; The Upper Lip Strain; Lateral Cephalogram; Orthodontic Treatment

\section{Introduction}

In orthodontic treatment, various analyzes are carried out to establish a case diagnosis which is then also useful in helping to develop the best treatment plan that can result in a good dentition, attractive smile and attractive profile. These three factors are part of a number of other factors that influence the aesthetic quality of a person's appearance. Cephalometric analysis can be used to determine the status of these three factors through several measurements of related parameters.
Orthodontic treatment involves movement of teeth that can change the position of the teeth in relation to the jawbone, both the maxilla and the mandible and the position of the maxillary teeth in relation to the mandible. In this regard, the Cephalometrics analysis as a means to obtain information on the initial position of the teeth and jaws are inseparable in the process of diagnosing an orthodontic case.

In practice, orthodontic treatment generally involves the movement of the teeth, especially the anterior teeth, because the impact 
of changing the position of the teeth in this area is believed to have a major and direct influence on a person's appearance. Thus, any changes that occur to the teeth in the anterior region, both upper and lower, will greatly affect a person's appearance and possibly a person's profile as well. Among several factors that affect a person' harmony profile is the nasolabial angle which can describe the position of the upper lip and the other is soft tissue parameters such as the Ricketts E-line which also informs the position of the upper and lower lips to the aesthetic line (E-line). Based on this thought, it is estimated that maxillary incisor angulation is closely related to upper lip strain which in turn affects the position of the upper lip in forming an attractive profile [2-5]. Therefore, this study was conducted with the aim of explaining the relationship between maxillary incisor angulation with upper lip strain. It is hoped that the information obtained will be useful in formulating an orthodontic treatment plan, especially in the management of cases of Class II division 1 malocclusion which requires correction of maxillary incisor angulation to obtain a better profile.

\section{Materials and Methods}

Fifty-two lateral cephalometric radiographs from the researcher's personal collection were used in this study. The case used in this study had an Angle class II division 1 malocclusion with an overjet greater than or equal to $6 \mathrm{~mm}$ and an overbite greater than or equal to $4 \mathrm{~mm}$. The determination of the classification of class II malocclusion in this case is based on the distocclusion molar relationship according to the Angle classification.

Furthermore, each lateral cephalogram is traced to facilitate the measurement. Measurement of maxillary incisor angulation was performed by calculating the angle formed by the long axis of the maxillary incisors and the S-N line (the line connecting the sella (S) and the nasion ( $\mathrm{N}$ ) point). As for the measurement of upper lip strain, the thickness of the upper lip is measured first, which is the horizontal distance from the point on the outer alveolar plate $2 \mathrm{~mm}$ below point A to the outer border of the upper lip (figure 1). Furthermore, for the upper lip strain, measurements were taken as the horizontal distance from the vermilion border of the upper lip to the labial surface of the maxillary central incisor (Figure 2) [2,6-10]

The measurement results for upper lip thickness and upper lip strain should be approximately the same or only have a difference

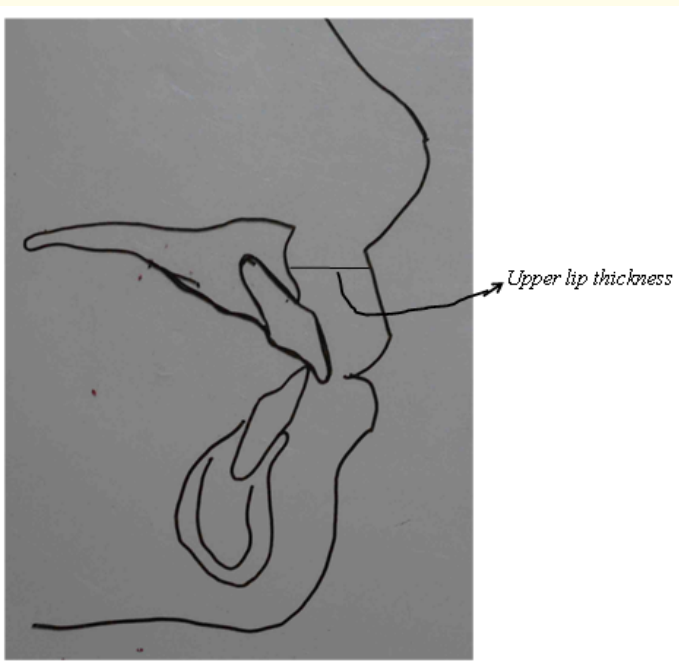

Figure 1: (Gambar 1) Upper lip thickness.

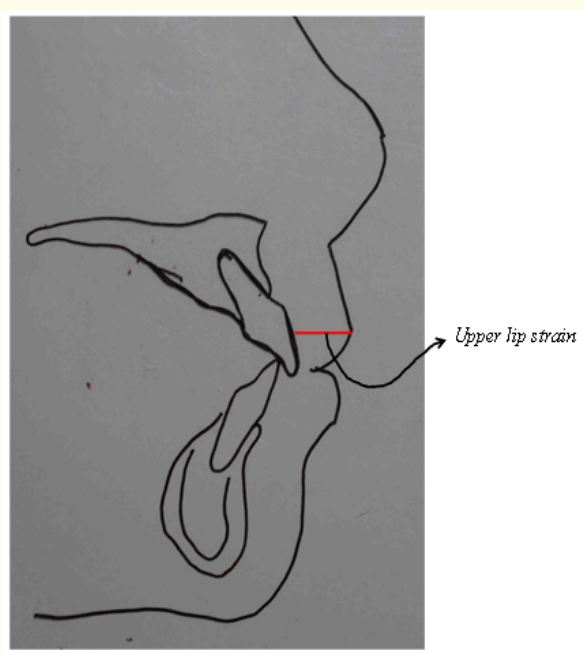

Figure 2: (Gambar 2) Upper lip strain.

of $1-2 \mathrm{~mm}$. If the upper lip strain is smaller than the upper lip thickness, then the lips are considered to be strained. For example, if the thickness of the upper lip is $15 \mathrm{~mm}$ and the lip strain is $8 \mathrm{~mm}$, so that the difference between the two measurements is $7 \mathrm{~mm}$, it is said that the lip strain factor in this case is 6 or $7 \mathrm{~mm}$. In this case, the understanding is that the maxillary incisors need to be retracted 6 or $7 \mathrm{~mm}$ so that the lips can achieve their normal shape and thickness [2]. 


\section{Results}

The results of the measurements carried out in this study, first underwent a distribution normality test to determine whether the subsequent statistical tests used parametric or non-parametric tests (Table 1).

\begin{tabular}{|c|c|c|c|c|c|c|c|}
\hline \multicolumn{8}{|c|}{ Tests of Normality } \\
\hline & \multirow{2}{*}{ Upper incisor angulation } & \multicolumn{3}{|c|}{ Kolmogorov-Smirnov } & \multicolumn{3}{|c|}{ Shapiro-Wilk } \\
\hline & & Statistic & df & Sig. & Statistic & df & Sig. \\
\hline \multirow{12}{*}{ Lip Strain } & 105 & ,260 & 2 & . & & & \\
\hline & 106 & ,260 & 2 & . & & & \\
\hline & 107 & ,292 & 3 & . & ,923 & 3 & ,463 \\
\hline & 109 & ,214 & 4 & . & ,957 & 4 & ,759 \\
\hline & 110 & ,311 & 6 &, 071 & ,829 & 6 & 104 \\
\hline & 111 &, 260 & 2 & $\cdot$ & & & \\
\hline & 112 & ,253 & 3 & . & ,964 & 3 & ,637 \\
\hline & 113 & ,278 & 4 & . & ,859 & 4 & 256 \\
\hline & 114 & ,225 & 4 & . & ,939 & 4 & ,649 \\
\hline & 115 & ,300 & 5 & ,161 & ,885 & 5 & ,335 \\
\hline & 117 &, 260 & 2 & . & & & \\
\hline & 118 & ,260 & 2 & . & & & \\
\hline
\end{tabular}

Table 1: Test the normality of the distribution of research data.

Data $<100 \diamond$ Sig Shapiro-Wilk.

Considering that the sample size in this study was smaller or less than 100, the Shapiro Wilk test was used. The results as shown in table 1 that significant value is greater than 0.05 which means that the data is normally distributed. Furthermore, parametric statistica; tests can be carried out with the Pearson correlation test (Table 2).

\begin{tabular}{|c|c|c|c|}
\hline \multicolumn{4}{|c|}{ Correlations } \\
\hline & & IRA-SN & $\mathbf{U L S}<\mathbf{U L T}$ \\
\hline \multirow{3}{*}{ IRA-SN } & Pearson Correlation & 1 & $.402^{*}$ \\
\hline & Sig. (2-tailed) & & .020 \\
\hline & $\mathrm{N}$ & 52 & 33 \\
\hline \multirow{3}{*}{ ULS $<$ ULT } & Pearson Correlation & $.402^{*}$ & 1 \\
\hline & Sig. (2-tailed) & .020 & \\
\hline & $\mathrm{N}$ & 33 & 33 \\
\hline
\end{tabular}

Table 2: Pearson correlation test.

*. Correlation is significant at the 0.05 level (2-tailed).
Table 2 shows the results of the Pearson correlation test between maxillary incisor angulation and upper lip strain. The value tested is when the difference between the two is more than $2 \mathrm{~mm}$ because the difference of $2 \mathrm{~mm}$ between the upper lip thickness and upper lip strain is still categorized as normal/acceptable. The Pearson correlation test shows that there is a significant relationship $(\mathrm{p}<0.05)$ between upper lip angulation and the strain factor. Twenty-four subjects (46\%) in this study showed upper lip strain above $2 \mathrm{~mm}$ based on the difference between upper lip thickness and upper lip strain measurements, as shown in table 3., and nine subjects $(17 \%)$ had upper lip strain within normal limits as shown in table 4 . However, there were at least nineteen subjects (37\%) who had an upper lip strain value greater than the upper lip thickness value with a difference of values in the range of 0.5 to $8 \mathrm{~mm}$ as shown in table 5 .

\section{Discussion}

The position of the upper lip is very important in determining the harmony of a person's profile, because the position of the 


\begin{tabular}{|c|c|c|c|c|}
\hline No & ULT & ULS & UI - SN & $\mathrm{ULS}<\mathrm{ULT}$ \\
\hline 1 & 17,5 & 15 & 110 & 2,5 \\
\hline 2 & 14 & 11,5 & 106 & 2,5 \\
\hline 3 & 15 & 12,5 & 111 & 2,5 \\
\hline 4 & 12,5 & 10 & 109 & 2,5 \\
\hline 5 & 12,5 & 10 & 89 & 2,5 \\
\hline 6 & 15 & 12 & 110 & 3 \\
\hline 7 & 17,5 & 14,5 & 125 & 3 \\
\hline 8 & 15 & 12 & 105 & 3 \\
\hline 9 & 15 & 12 & 132 & 3 \\
\hline 10 & 15 & 12 & 114 & 3 \\
\hline 11 & 15 & 12 & 110 & 3 \\
\hline 12 & 15 & 12 & 107 & 3 \\
\hline 13 & 15,5 & 12 & 107 & 3,5 \\
\hline 14 & 16 & 12,5 & 115 & 3,5 \\
\hline 15 & 14 & 10 & 113 & 4 \\
\hline 16 & 16 & 12 & 120 & 4 \\
\hline 17 & 18,5 & 14,5 & 112 & 4 \\
\hline 18 & 12 & 8 & 109 & 4 \\
\hline 19 & 16,5 & 12 & 110 & 4,5 \\
\hline 20 & 16,5 & 12 & 130 & 4,5 \\
\hline 21 & 15,5 & 10,5 & 118 & 5 \\
\hline 22 & 16 & 11 & 134 & 5 \\
\hline 23 & 16,5 & 11 & 114 & 5,5 \\
\hline 24 & 19 & 13 & 117 & 6 \\
\hline
\end{tabular}

Table 3: Subjects with upper lip strain above $2 \mathrm{~mm}$.

\begin{tabular}{|l|c|c|c|c|}
\hline No & ULT & ULS & I RA - SN & ULS < ULT \\
\hline 1 & 12 & 11 & 109 & 1 \\
\hline 2 & 11 & 10 & 95 & 1 \\
\hline 3 & 16 & 15 & 113 & 1 \\
\hline 4 & 9 & 8 & 111 & 1 \\
\hline 5 & 14,5 & 13 & 105 & 1,5 \\
\hline 6 & 16,5 & 15 & 107 & 1,5 \\
\hline 7 & 14 & 12,5 & 118 & 1,5 \\
\hline 8 & 13 & 11 & 108 & 2 \\
\hline 9 & 12 & 10 & 102 & 2 \\
\hline
\end{tabular}

Table 4: Subjects with upper lip strain within normal limits.

\begin{tabular}{|l|c|c|c|c|}
\hline No & ULT & ULS & I RA - SN & ULS < ULT \\
\hline 1 & 12 & 12,5 & 115 & 0,5 \\
\hline 2 & 15 & 16 & 106 & 1 \\
\hline 3 & 16 & 17 & 115 & 1 \\
\hline 4 & 15 & 16,5 & 113 & 1,5 \\
\hline 5 & 11 & 12,5 & 115 & 1,5 \\
\hline 6 & 12,5 & 14 & 116 & 1,5 \\
\hline 7 & 15 & 16,5 & 113 & 1,5 \\
\hline 8 & 12 & 14 & 110 & 2 \\
\hline 9 & 12 & 14 & 114 & 2 \\
\hline 10 & 12 & 14 & 112 & 2 \\
\hline 11 & 12 & 14 & 117 & 2 \\
\hline 12 & 15 & 17,5 & 110 & 2,5 \\
\hline 13 & 14 & 16,5 & 109 & 2,5 \\
\hline 14 & 11 & 14 & 126 & 3 \\
\hline 15 & 13 & 16 & 115 & 3 \\
\hline 16 & 17,5 & 21,5 & 114 & 4 \\
\hline 17 & 7 & 12 & 112 & 5 \\
\hline 18 & 12 & 20 & 104 & 8 \\
\hline 19 & 8 & 16 & 122 & 8 \\
\hline
\end{tabular}

Table 5: Subjects with upper lip strain greater than upper lip thickness.

upper lip is one of the components in profile analysis which will determine whether the result is straight, convex or concave. On the other hand, the position of the upper lip is also influenced by several factors, including upper lip strain, upper lip thickness and maxillary incisor angulation. As a fairly important facial aesthetic parameter, changes to the size and prominence of the lips can be done in various ways, either directly or indirectly. Directly, these changes can be accomplished through vermilion reduction surgery or through lip augmentation with fillers, while indirect procedures involve moving the upper and/or lower incisors in a sagittal direction which may also involve a dentoalveolar component or orthognathic surgery which will cause various effects on the prominence of the lips according to the characteristics of the soft tissue [11,12] One of the most well-known soft tissue parameters, which can describe the prominent position of the lips, is the aesthetic line proposed by Ricketts. This aesthetic line connects the tip of the nose with the most prominent point of the chin soft tissue in profile view $[13,14]$. 
In relation to this prominent lip, there are various opinions from a number of studies which show how many different assessments or points of view on the lips in their supportive role on a person's facial profile, but at the same time this shows how individual it is so that appreciation should be given priority to individual wishes and opinions in the analysis and treatment decisions that follow. Among these opinions, Coleman et.al found that for extreme prognathic and retrognathic profiles, the characteristic of full lips was preferred and the same preference was also seen in both male and female with prominent chin and tip nose characteristics according to Czarnecki., et al. $[15,16]$ A number of other studies have even linked this prominent lip preference with ethnic variations in the observations of research participants and included here is that of Hall., et al. who found that the research participants preferred the profile of a sample of African-American ethnicity in which the upper and lower lips were more prominent than the profile of a sample of Caucasoid subjects [17]. Slightly different views were found among young orthodontists according to the results of Battle., et $a l$. who stated that the profile with more prominent lips seemed more attractive or good because in the view of these young orthodontists, the application of standards adapted to ethnic or racial preferences needed to be considered because in their work, orthodontists would deal with patients from various ethnicities or races [18].

Considering that a harmonious profile is one of the goals in orthodontic treatment, some of the factors mentioned above need to be considered in developing a treatment plan, especially in patients who have a main complaint of a convex facial profile. In this patient, awareness of his profile is clearly seen based on his desire to undergo orthodontic treatment which can change the profile as expected. Thus, it is important for orthodontists to consider various attempts to produce a harmonious profile and one of the factors here is maxillary incisor angulation which is the main area of orthodontic correction. Maxillary incisor angulation is one of the factors that has been shown to have a significant relationship with upper lip tension as can be seen in table 2. Based on the results of this study, it can be understood that changes in maxillary incisor angulation will affect the upper lip strain, and since the upper lip strain is related to the position of the upper lip, changes in the angulation of the maxillary incisors will affect the position of the upper lip and ultimately the harmony of a person's profile.

In practice, it is understood that if the upper lip tension value is less than $2 \mathrm{~mm}$ from the upper lip thickness, then the strain factor is considered to be within normal limits. However, if the difference in the value of the upper lip tension to the thickness of the upper lip is more than $2 \mathrm{~mm}$, it can be concluded that the patient requires retraction of the maxillary incisors to the extent of the value of the difference, because the lips are considered to be in a strained condition. However, if the maxillary incisor retraction continues beyond this value, it is said that the lip position will not be affected by the position of the retracted incisor. So in this case, the position of the lips does not always follow the movement of retraction of the maxillary incisors, although it is also understood that thin lips will more easily adapt to the retraction of the teeth. This fact can be taken into consideration in dealing with the patient's wishes, because orthodontists can predict the extent of changes that can be caused through orthodontic treatment. This is important so that patients can understand that orthodontic treatment that is expected to produce a change in the profile has limitations so that it does not cause disappointment at the end of treatment.

In this study, only 11 (21\%) of the subjects had normal upper lip thickness (15 mm) as shown in Tables 3,4 and 5. Meanwhile, the number of subjects with normal lip strain, i.e., $<2 \mathrm{~mm}$ of the score of the thickness of the upper lip is nine or $17 \%$. Of the nine subjects with normal lip tension, there were 2 (22\%) who had a lip thickness above the normal value of $15 \mathrm{~mm}$, while the remaining seven subjects (78\%) had an upper lip thickness below the normal value of $15 \mathrm{~mm}$. This means that most of the subjects with normal lip tension in this study had thinner lips and were more adaptable to lip tension.

\section{Conclusion}

This study has proven that there is a significant relationship between maxillary incisor angulation and upper lip strain. This informative fact is expected to be useful for dentists, especially orthodontists in preparing treatment plans related to lip position and therefore also the esthetics of the patient's profile. However, it should also be borne in mind that in reality, thick lips do not always follow tooth movement, in contrast to thin lips which tend to exhibit the characteristics of following or better adapting to tooth movement [2].

\section{Acknowledgment}

The researcher expresses his deepest gratitude to those who have provided support so that this research can be carried out properly and smoothly. 


\section{Bibliography}

1. Mendes LM., et al. "Long-term profile attractiveness in class II division 1 malocclusion patients treated with and without extractions". American Journal of Orthodontics and Dentofacial Orthopedics 155 (2019): 362-371.

2. Jacobson A. "Radiographic Cephalometry from Basic to Videoimaging”. Quintessence Publishing, Co. Inc. Hongkong (2006): 53-64.

3. Phulari BS. "An Atlas on Cephalometric Landmarks". Jaypee Brothers Medical Publishers (P) Ltd. New Delhi (2013): 3-6.

4. Siqueira de Lima L., et al. "Evaluation of Facial soft tissue thickness in symmetric and asymmetric subjects with the use of cone-beam computed tomography". American Journal of Orthodontics and Dentofacial Orthopedics 155 (2019): 216-223.

5. Premkumar S. "Orthodontics, Prep. Manual for Undergraduates”. Elsevier, New Delhi (2008): 207-232.

6. Bergersen RO. "Enlargement and distortion in Cephalometric Radiography. Compesation tables for linear measurements". The Angle Orthodontist 56.3 (1990): 230-244.

7. Barbosa De Lima AP., et al. "Influence of facial pattern in smile attractiveness regarding gingival exposure assessed by dentist and laypersons". American Journal of Orthodontics and Dentofacial Orthopedics 155 (2019): 224-233.

8. Johnson JS. "A New Approach to cephalometric analysis of the dental base relationship". The Angle Orthodontist 48.1 (1998): 23-32.

9. Alpern MC. "Clinical Radiography in the orthodontic practice". The Angle Orthodontist 54.3 (1984): 233-246.

10. Kvam E and Krogstad O. "Correspondence of Cephalometric Values, A methodologic study using duplicating films of lateral head plates". Dental Institute of Experimental research, University of Oslo, Blindern, Oslo, Norway 42.2 (1972): 123-128.

11. Naini FB. "Facial Aesthetic: Concept and Clinical Diagnosis". Oxford, United Kingdom: Wiley-Blackwell (2011).

12. Gill DS., et al. "The Facial Soft Tissue Effect of Orthognathic Surgery". Facial Plastic Surgery 33 (2017): 519-525.

13. Ricketts RM. "Planning Treatment on the basis of the facial pattern and an estimate of its growth". The Angle Orthodontist 27 (1957): 14-37.
14. Ricketts RM. "Cephalometric Analysis and Synthesis". The Angle Orthodontist 31 (1961): 141-156.

15. Coleman GG., et al. "Influence of chin prominence on esthetic lip profile preference". American Journal of Orthodontics and Dentofacial Orthopedics 132 (2007): 36-42.

16. Czarneckim ST., et al. "Perceptions of a balanced Facial profile". American Journal of Orthodontics and Dentofacial Orthopedics 104 (1993): 180-187.

17. Hall D., et al. "The perception of optimal profile in African Americans versus White Americans as assessed by orthodontists and the lay public". American Journal of Orthodontics and Dentofacial Orthopedics 118 (2000): 514-525.

18. Battle Y., et al. "Disparity in opinion on lip protrusiveness in contemporary African American faces". The Korean Journal of Orthodontics 48 (2018): 23-29.

\section{Assets from publication with us}

- Prompt Acknowledgement after receiving the article

- Thorough Double blinded peer review

- Rapid Publication

- Issue of Publication Certificate

- High visibility of your Published work

Website: www.actascientific.com/

Submit Article: www.actascientific.com/submission.php

Email us: editor@actascientific.com

Contact us: +919182824667 